\title{
Effects of Central Administration of Bisphenol A on Behaviors and Growth in Chicks
}

\author{
Kouichi Sashihara, Atsushi Ohgushi, Ryuichi Ando, Tomoe Yamashita, \\ Tomo Takagi, Tomonori Nakanishi, Takao Yoshimatsu \\ and Mitsuhiro Furuse
}

Laboratory of Advanced Animal and Marine Bioresources, Graduate School of Bioresource and Bioenvironmental Sciences, Kyushu University, Fukuoka 812-8581, Japan

\begin{abstract}
We investigated the central effect of the estrogenic pollutant, bisphenol A (BPA), on behaviors, growth and several organ weights in chicks.

Four-day-old male chicks were injected into the brain with BPA at doses of 0,100 , $200 \mu \mathrm{g}$. Food intake and body weight gain were determined, but no significant effects of BPA were detected. Secondly, behaviors of these chicks were tested under an isolated situation. The behaviors such as frequency of jumping, distress vocalization and duration of crouching were monitored. Central injection of BPA increased distress vocalizations in a dose-dependent manner, though no significant changes were observed in other indices. Thereafter, four organ (testis, kidney, liver and brain) weights were measured. No significant differences in all the organs were detected among all treatments.

These results suggest that the accumulation of BPA in the central nervous system may somewhat induce the behavioral change in a stressful situation.
\end{abstract}

Key words : bisphenol A, central administration, behavior, chicks

\section{Introduction}

For half a century, surfaced effects of environmental chemicals for the incidence of reproductive abnormalities in male have been reported in wildlife animals and humans (Fry, 1995 ; Guillette et al., 1995). It has been suggested that these evidences may be attributable to the presence of chemicals with estrogenic activity in our environments.

One of the compounds, bisphenol A (BPA), is the monomeric unit widely used to produce the ubiquitous plastic, polycarbonate. BPA has been known to exert estrogenic effects (Dodds and Lawson, 1938). BPA induced expression of estrogenresponsive genes and promoted proliferation in MCF-7, a breast cancer cell line (Krishnan et al., 1993). In rats, BPA induced prolactin synthesis and release in vivo and in vitro (Steinmetz et al., 1997) as well as inducing growth differentiation and c-fos

Received : April 9, 2001 Accepted : May 23, 2001

Correspondence should be addressed to: Dr. M. Furuse, Laboratory of Advanced Animal and Marine Bioresources, Graduate School of Bioresource and Bioenvironmental Sciences, Kyushu University, Fukuoka 812-8581, Japan Tel. and Fax : (81) (92) 642-2953 E-male : furuse@brs.kyushu-u.ac.jp. 
gene expression in the uterus and vagina (Steinmetz et al., 1998). In mice, BPA can affect the development of reproductive organs and their function in the male offspring of mothers treated with BPA during pregnancy (Vom Saal et al., 1998).

In wild birds, abnormal behaviors, lacks in breeding and reproduction (Broley, 1958), loss of expression of territoriality, poor parenting, female-female pairing, and feminization (Rattner et al., 1984 ; Fry et al., 1987) have been observed. It was considered that these evidences were caused by effects of organochlorine contaminants (Rattner et al., 1984). However, many synthetic chemicals except for organochlorine contaminants exist widely in the environment. Involvements of other contaminants such as BPA should be also investigated. However, the effect of BPA in vivo is still unclear. Furthermore, little is known about the central effects of neonatal exposure with BPA in birds.

In the present study, we evaluated the effects on the behaviors and growth of central administration with BPA at relatively acute dose levels in chicks.

\section{Materials and Methods}

\section{Animals and central injection}

In this experiment, male layer type chicks (Julia) purchased from a local hatchery (Murata Hatchery, Fukuoka, Japan) were housed in a windowless room at a constant temperature of $28^{\circ} \mathrm{C}$. Lighting was provided continuously. The birds were given free access to a commercial starter diet (Toyohashi Feed and Mills Co. Ltd., Aichi, Japan) and water. The birds were distributed into experimental groups based on their body weight, so that the average body weight was as uniform as possible for each treatment.

BPA was purchased from Sigma (St. Louis, MO, USA) and dissolved in a $10 \%$ ethanol solution, which was prepared in a sesame oil (Katayama Co, Osaka, Japan). Birds (4-day-old) under ad libitum feeding were injected into the brain with three levels $(0,100$ and $200 \mu \mathrm{g} / 2 \mu l)$ of BPA using a microsyringe according to the method of Davis et al. (1979). Ethanol levels are identical in all treatments. After central administration of BPA three experiments described below were done successively. The effect of BPA on food intake was investigated at early stages after treatment. Thereafter, tests for other behaviors were done and finally organ weights were measured.

Food intake and body weight gain

The birds were allowed access to the diet for $6 \mathrm{~h}$ immediately after injection with BPA. Food intake was determined by measuring the disappearance of food from the pre-weighted feeder. The weight of feeders was measured by using an electric digital balance of precision $\pm 1 \mathrm{mg}$. The body weights were also determined day by day for 3 days after treatments.

The number of birds used was as follows : control, 13 ; $100 \mu \mathrm{g}, 12$; and $200 \mu \mathrm{g}, 12$. Behavioral study

After the investigation of food intake and body weight gain, we randomly took 7 birds from each treatment for the behavioral study. The birds were marked individually and were kept together in the same cage over 8 days. Then, each bird was distressed by isolation. The bird was individually moved to monitoring cage $(30 \times 40$ 
$\mathrm{cm}$ with 20-cm-high side walls) whose floor was divided into 12 squares. The behaviors of each bird were monitored by video recording and the audio analysis application (CSRE 4.5 ; AVAAZ Innovations Inc., London, Canada) to collect data every second for $5 \mathrm{~min}$. Frequency of jumping and distress vocalization were counted, while locomotor activity was recorded as the number of squares crossed. Duration of crouching was also measured.

\section{Measurement of organs}

The birds were killed by decapitation at 20-day-old and four organs (liver, kidney, testis and brain) were removed. Those were weighed by using an electric digital balance of precision $\pm 1 \mathrm{mg}$.

The number of birds used was as follows : control, $10 ; 100 \mu \mathrm{g}, 8$; and $200 \mu \mathrm{g}, 9$. Statistical analysis

Data were analyzed by one-way ANOVA by the General Linear Model procedure using a commercially available package (SAS, 1985), comparisons between means were made using Duncan's multiple range test. The results are presented as means $\pm \mathrm{SEM}$.

\section{Results and Discussion}

In the present study, we investigated the effect of BPA in vivo from the various aspects when injected into the brain. None of the chicks treated with BPA was weaken or dead. There were no evident signs of acute toxicity by central administration with BPA.

Table 1 (A) shows the cumulative food intake in 4-day-old male chicks following the central injection of BPA. BPA had no effect on food intake of chicks. Table 1 (B) demonstrates the body weight gain under ad libitum feeding for 3 days after treatments. There was no significant difference in body weight gain between control and two BPA treated groups. Although BPA induced the suppression of body weight

Table 1. Cumulative food intake (A) and body weight gain (B) of the chick after central administration of bisphenol A (BPA ; 0,100 or $200 \mu \mathrm{g}$ )

\begin{tabular}{cccc}
\hline \hline \multicolumn{4}{c}{$(\mathrm{A})$ Food intake $(\mathrm{g})$} \\
\hline Time after treatments & \multicolumn{1}{c}{ Control } & $100 \mu \mathrm{g}$ & $200 \mu \mathrm{g}$ \\
\hline $30 \mathrm{~min}$ & $1.80 \pm 0.10$ & $1.17 \pm 0.16$ & $1.88 \pm 0.16$ \\
$60 \mathrm{~min}$ & $1.98 \pm 0.11$ & $1.93 \pm 0.16$ & $2.07 \pm 0.17$ \\
$120 \mathrm{~min}$ & $2.53 \pm 0.14$ & $2.51 \pm 0.20$ & $2.66 \pm 0.19$ \\
$360 \mathrm{~min}$ & $4.36 \pm 0.21$ & $4.38 \pm 0.27$ & $4.74 \pm 0.29$ \\
\hline \multicolumn{4}{c}{ (B) Body weight gain (g) } \\
\hline $4 \mathrm{~h}$ & $8.7 \pm 2.3$ & $8.8 \pm 1.6$ & $9.4 \pm 1.8$ \\
$72 \mathrm{~h}$ & $16.5 \pm 2.9$ & $16.0 \pm 1.9$ & $16.8 \pm 2.4$ \\
& $23.3 \pm 3.1$ & $24.8 \pm 3.4$ & $23.4 \pm 2.9$ \\
\hline
\end{tabular}

The number of birds used was as follows: control, $13 ; 100 \mu \mathrm{g}, 12 ; 200 \mu \mathrm{g}, 12$.

Values are means \pm S.E.M. 
Table 2. Behaviors over $5 \mathrm{~min}$ of chicks after central administration of bisphenol A (BPA ; 0, 100 or $200 \mu \mathrm{g}$ )

\begin{tabular}{cccc}
\hline \hline Treated group & Locomotion $^{1}$ & Jump $^{2}$ & Crouch $^{3}$ \\
\hline Control & $15.3 \pm 9.1$ & $1.14 \pm 0.99$ & $134 \pm 46$ \\
$100 \mu \mathrm{g}$ & $38.3 \pm 14.5$ & $2.71 \pm 2.39$ & $31 \pm 22$ \\
$200 \mu \mathrm{g}$ & $25.4 \pm 9.1$ & $2.14 \pm 0.86$ & $77 \pm 41$ \\
\hline
\end{tabular}

The number of birds used was follows : control, $7 ; 100 \mu \mathrm{g}, 7 ; 200 \mu \mathrm{g}, 7$. Values are means \pm S.E.M. 1, total numbers of square crossed. 2, total numbers of jumping. 3 , total duration of crouching.

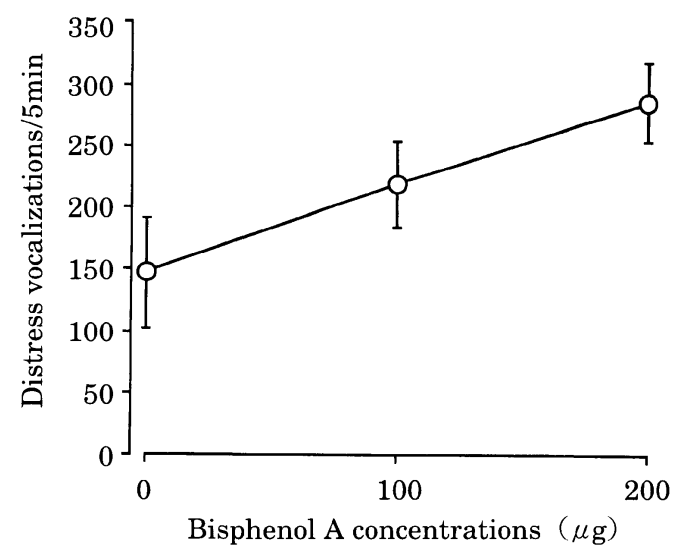

Fig. 1. Distress vocalization over $5 \mathrm{~min}$ of the chicks after central administration of bisphenol A (BPA; 0,100 or $200 \mu \mathrm{g}$ ). The number of birds used was follows : control, $7 ; 100 \mu \mathrm{g}, 7 ; 200 \mu \mathrm{g}, 7$. Values are means \pm S.E.M. Distress vocalization $=148(\mathrm{SE} 34)+$ 0.69 (SE 0.26) $\mathrm{x}, \mathrm{r}=0.521, \mathrm{P}<0.05$.

gain and increase in food consumption in mice (Furukawa et al., 1994), central administration of BPA in this study did not affect normal growth of neonatal chicks. This indicates that effect of BPA depends on the kinds of species (mammals or bird) or injected routes (central or oral) of BPA.

After 8 days of central injection with BPA, we investigated the behavior of chicks under the isolation stress in experiment 2. As shown in Table 2, no significant changes were observed in locomotion, jumping and crouching of chicks. Fig. 1 shows the central effect of BPA on distress vocalization. Distress vocalization linearly increased by BPA in a dose-dependent manner. Many neurochemicals participate in the control of isolation distress and many pharmacological ways can change the frequency of distress vocalization. Agents for the regulation of distress vocalization have been reported as follows: glucagon-like peptide-1 (Panksepp et al., 1997), oxytocin (Panksepp, 1992), opioids (Vilberg et al., 1984), and clonidine (Rossi et al., 1983) reduce distress vocalization, while various glutamate receptor agonists and cor- 
Table 3. Four organ (brain, testis, liver, kidney) and body weights of 20 days-old chicks treated with bisphenol A $(0,100$ or $200 \mu \mathrm{g})$

\begin{tabular}{lcccc}
\hline \hline \multirow{2}{*}{ Organs } & & \multicolumn{3}{c}{ Treated groups } \\
\cline { 3 - 5 } & & Control & $100 \mu \mathrm{g}$ & $200 \mu \mathrm{g}$ \\
\hline Brain & $(\mathrm{g})$ & $1.56 \pm 0.027$ & $1.57 \pm 0.032$ & $1.55 \pm 0.015$ \\
Liver & $(\mathrm{g})$ & $4.59 \pm 0.21$ & $4.90 \pm 0.15$ & $4.83 \pm 0.15$ \\
Kidney & $(\mathrm{g})$ & $1.65 \pm 0.06$ & $1.79 \pm 0.058$ & $1.72 \pm 0.069$ \\
Testis & $(\mathrm{g})$ & $0.035 \pm 0.0024$ & $0.037 \pm 0.002$ & $0.033 \pm 0.0024$ \\
Body weight & $(\mathrm{g})$ & $140 \pm 4$ & $146 \pm 3$ & $143 \pm 4$ \\
\hline
\end{tabular}

The number of birds used was as follows : control, $10 ; 100 \mu \mathrm{g}, 8 ; 200 \mu \mathrm{g}, 9$. Values are means \pm S.E.M.

ticotrophin releasing hormone (CRF) (Panksepp et al., 1997) elevate. Estrogens stimulate CRF gene expression in vitro (Vamvakopoulos et al., 1993) and may affect the modulation of synthesis or secretion of CRF in vivo (Whitnall, 1993). The change of distress vocalization in this experiment may be caused by the estrogenic activity of BPA, since distress vocalization was enhanced by the central action of BPA. This finding indicates that the neonatal exposure to BPA or the accumulation of the BPA in the fertilized egg may affect the central nervous system. It is reported that perinatal exposure to BPA affects the behavior involved in the motivation to explore and anxiety in mice (Frabollini et al., 1999). BPA dramatically decreased plasma free teststerone levels in mice (Takao et al., 1999). These facts suggested that BPA could directly or indirectly change neuronal function in the brain. However, behavior as the final point of cascade of events may reveal subtle effects not easily detectable at each single step of the process. The mechanism underlying the increase of distress vocalization response to BPA is still obscure. More detail studies needed to clarify this mechanism.

Table 3 shows the weights of four organs in experiment 3 . There were no differences in all organ weights among treatments. In mice, maternal exposure to BPA increased the size of the prepubertal testis and reduced the size of epididymus (Vom Saal et al., 1998). Absorption of large quantities of BPA through the skin was resulted in extensive damage to kidneys and liver (Atkinson and Roy, 1995). However, the acute central administration of BPA in a neonatal stage did not affect testis, kidney and liver weight. Thus, it is suggested that changes in organ weight previously reported are direct and/or indirect effects of BPA at peripheral levels, but not through the acute action of the central nervous system.

In conclusion, these findings indicate that the potency of BPA in the central nervous system could partly alter the behaviors under the stressful situation.

\section{Acknowledgments}

This study was supported by a grant-in-aid for scientific research from the Ministry of Education, Science and Culture, Japan and Uehara Memorial Foundation. 


\section{References}

Atkinson A and Roy D. In vitro conversion of environmental estrogenic chemical bisphenol A to DNA binding metabolite(s). Biochemical and Biophysical Research Communications, 210 : 424-433. 1995.

Broley CL. The plight of the American bald eagle. Audubon Magazine, 60 : 162-163, 171. 1958.

Davis JL, Masuoka DT, Gerbrandt LK and Cherkin A. Autoradiographic distribution of L-proline in chicks after intracerebral injection. Physiology \& Behavior, 22 : 693-695. 1979.

Dodds EC and Lawson W. Molecular structure in relation to oestrogenic activity. Compounds without a phenanthrene nucleus. Proceedings Royal Society, London B 125 : 222-232. 1938.

Farabollini F, Porrini S and Dessi-Fulgheri, F. Perinatal exposure to the estrogenic pollutant bisphenol A affects behavior in male and female rats. Pharmacology, Biochemistry and Behavior, 64 : 687-694. 1999.

Fry DM, Toone CK, Speich SM and Peard RJ. Sex ratio skew and breeding patterns of gulls. Studies in Avian Biology, 10 : 26-43. 1987.

Fry DM. Reproductive effects in birds exposed to pesticides and industrial chemicals. Environmental Health Perspectives, 103 : 165-171. 1995.

Furukawa F, Nishikawa A, Mitsui M, Sato M, Suzuki J, Imazawa T and Takahashi M. A 13 -week subchronic toxicity study of bisphenol A in B6C3F1 mice (Japanese with English summary). Bulletin of National Institute of Hygienic Sciences, 112 : 89-96. 1994.

Guillette Jr. LJ, Crain DA, Rooney AA and Pickford DB. Organization versus activation : the role of endocrine-disrupting contaminants (EDCs) during embryonic development in wildlife. Environmental Health Perspectives, 103 : 157-164. 1995.

Krishnan AV, Stathis P, Permuth SF, Tokes L and Feldman D. Bisphennol-A : an estrogenic substance is released from polycarbonate flasks during autoclaving. Endocrinology, 132 : 2279-2286. 1993.

Panksepp J. Oxytocin effects on emotional processes : Separation distress, social bonding, and relationships to psychiatric disorders. Annals of the New York Academy of Sciences, 652 : 243-252. 1992.

Panksepp J, Nelson E and Bekkedal M. Brain systems for the mediation of social separationdistress and social reward. Annals of the New York Academy of Sciences, 807 : 78-100. 1997.

Rattner BA, Eroschenko VP, Fox GA, Fry DM and Gorsline J. Avian endocrine responses to environmental pollutants. Journal of Expexperimental Zoology, 232 : 683-689. 1984.

Rossi J III, Sahley TL and Panksepp J. The role of brain norepinephrine in clodinine suppression of isolation-induced distress in the domestic chick. Psychopharmacology, $79: 338-342$. 1983.

SAS, SAS user's guide : Statistics. SAS Institute, Cary. 1985.

Steinmetz R, Mitchner NA, Grant A, Allen DL, Bigsby RM and Ben-Jonathan N. The xenoestrogen bisphenol A induces growth, differentiation, and c-fos gene expression in the female reproductive tract. Endocrinology, $139: 2741-2747.1998$.

Steinmetz R, Brown NG, Allen DL, Bigsby RM and Ben-Jonathan N. The environmental estrogen bisphenol A stimulates prolactin release in vitro and in vivo. Endocrinology, 138 : 1780-1786. 1997.

Takao T, Nanamiya W, Nagano I, Asaba K, Kawabata K and Hashimoto K. Exposure with the environmental estrogen bisphenol A disrupts the male reproductive tract in young mice. Life Science, $65: 2351-2357.1999$.

Vamvakopoulos NC and Chrousos GP. Evidence of direct estrogenic regulation of human corticotropin-releasing hormone gene expression. Journal of Clinical Investigation, $92: 1896$ $-1902.1993$.

Vilberg TR, Panksepp J, Kastin AJ and Coy DH. The pharmacology of endorphin modulation of chick distress vocalization. Peptides, 5 : 823-831. 1984.

Vom Saal FS, Cooke PS, Buchanan DL, Palanza P, Thayer KA, Nagel SC and Welshons WV. A physiologically based approach to the study of bisphenol A and other estrogenic chemicals on 
the size of reproductive organs, daily sperm production, and behavior. Toxicology and Industrial Health, 14 : 239-260. 1998.

Whitnall MH. Regulation of the hypothalamic corticotropin-releasing hormone neurosecretory system. Progress in Neurobiology, 40 : 573-629. 1993. 